\title{
Types of Environmental Licensing: An Analysis of the Temporal Evolution in Brazil
}

\author{
André Cavalcante da Silva Batalhão ${ }^{1,3,}$, Alessandra Chacon², Emiliano Lôbo de Godoi ${ }^{3}$, \\ Denílson Teixeira $^{3}$ \\ ${ }^{1}$ Center for Environmental and Sustainability Research, New University of Lisbon, Caparica, Portugal \\ ${ }^{2}$ Postgraduate Program in Environment, University of Rio de Janeiro State, Rio de Janeiro, Brazil \\ ${ }^{3}$ School of Civil and Environmental Engineering, Federal University of Goiás, Goiânia, Brazil
}

Email address:

andre.ciamb.ufg@gmail.com (A. C. da S. Batalhão)

${ }^{*}$ Corresponding author

\section{To cite this article:}

André Cavalcante da Silva Batalhão, Alessandra Chacon, EmilianoLôbo de Godoi, DenílsonTeixeira. Types of Environmental Licensing: An Analysis of the Temporal Evolution in Brazil. International Journal of Environmental Protection and Policy. Vol. 6, No. 1, 2018, pp. 9-13. doi: 10.11648/j.ijepp.20180601.12

Received: December 7, 2017; Accepted: December 18, 2017; Published: January 10, 2018

\begin{abstract}
Environmental licensing has become an important instrument in the defense of natural resources and ecological balance. Environmental licensing is a legal requirement to which all companies or activities that use natural resources or that may cause some kind of pollution or degradation to the environment. It is an administrative procedure by which the location, installation, expansion and operation of these enterprises and / or activities are authorized. Responsibility for the concession is supported by the state environmental agencies and, depending on the case, also of the Brazilian Institute for the Environment and Renewable Natural Resources (IBAMA), in the case of large projects with the potential to affect more than one State. The aim of this research was to evaluate and present by systematic quantitative method the evolution of the quantity of licenses in Brazil in the last 11 years and types of licenses. For this, secondary data from IBAMA was collected. Nowadays in Brazil the types of license most demanded are electric transmission lines, hydroelectric projects and construction of highway. Investments in infrastructure are directly close to sectored policies and macroeconomic actions of national interest.
\end{abstract}

Keywords: Environmental Licensing, Natural Resources, Brazil

\section{Introduction}

In the late 1960 s the environmental debate was guided by new problems and weaknesses that modernity was bringing to the world. Therefore several themes related to the environment and societies were considered in the reflections about this new reality [1].

The disorderly pursuit of economic growth and the everincreasing demand for consumer goods could be take the world to the exhaustion of natural resources and to a collapse for the future of the planet. Using this idea, in 1971 the Club of Rome published your first report entitled "Limits of Growth". This report had a major impact around the world and concluded that the growth needed to be controlled to avoid a deep crisis.

The Club of Rome concluded that the degradation of the environment was result of the uncontrolled growth of the population and the demand for natural resources on planet [2]. From this moment the world perceived that the presence of laws and instruments of environmental management would be indispensable tools for the present and future [3].

A productive activity depends of Approval State and should consent the current Brazilian laws to reduce the potential risk for environmental balance and quality of life human [4]. Environmental licensing is an administrative procedure which a competent environmental body from the Federal or State or Municipal levels to grant licenses the implementation, operation or expansion of potentially environmentally degrading ventures [5].

In Brazilian case it's important to highlight that the issues regarding the environment protection are centralized in the SISNAMA (National Environmental System), which is 
composed by bodies and agencies of the Union, States, Federal District, the Municipalities and the Foundations established by governmental agencies responsible for the protection and improvement of environmental quality. The SISNAMA has the following structure:

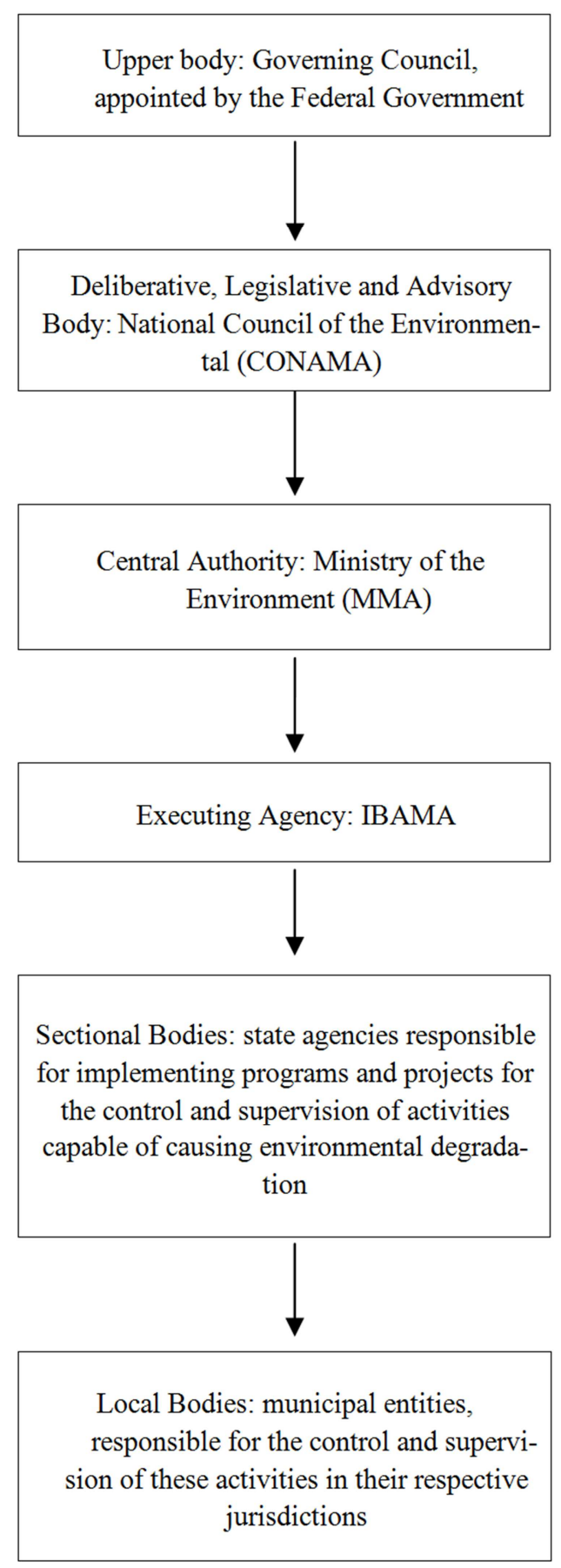

Figure 1. SISNAMA structure.

Established by the National Environmental Policy (PNMA) the Law no. 6.938 / 1981 has demonstratinga relevant instrument. The goal of PNMA is to preserve, improve and recover the environmentally quality of life ensuring conditions for socioeconomic development, national security interests and the protection of the dignity of human life. At that time it was innovative and later incorporated into the Federal Constitution of 1988, and this vision remains extremely current and increasingly necessary, as environmental degradation has advanced through human activities [6].

As a theoretical basis the social aspects were the main problem on conflicts related to the environmental licensing process [7]. The dispute between public agencies can delay the licensing processes and generating operational difficulties in the process that should be solved by the judicial system. The crucial question is how to create conflict resolution mechanisms among the different actors that will minimize the potential inefficiencies of a decentralized licensing process. The best response seems to be to create administrative instances that serve as a forum for negotiation to reduce costs arising from the judicial conflicts. Based on data obtained from the Brazilian Institute of Environment and Natural Renewable Resources (IBAMA) and other sources as state licensing agencies The Environmental Licensing in Brazil needs to advance empirical knowledge about this theme. Additionally it is necessary to generate a network platform for discussion of this PNMA instrument to elaborate recommendations to continuing the improvement process to minimize conflicts [6].

The legal importance of environmental licensing in Brazil, especially to activities and ventures with low impact potential, the number of studies in this country that approached this topic has been reduced. This situation is considered dangerous, considering that the Public Ministry of some states and some authors and institutions have questioned the effectiveness of the processes and simplified studies of environ-mental licensing [8].

There are several types of environmental licensing. The Law n. 6.938 / 81 establishes in article 10 that the construction, installation, expansion and operation of businesses and activities that use natural resources, considered potentially and effectively polluters and capable of causing environmental degradation depend on environmental licensing.

The Resolution n. 237 of 19.12.1997 of the National Environmental Council - CONAMA establishes the types of licensing authorized by the Government:

1. Previous License: granted in the preliminary phase of the planning of the enterprise or activity to approve location and design to attest the environmental feasibility and establishing the basic requirements and conditions to be met in the next phases of this implementation;

2. Installation License: authorizes the installation of the enterprise or activity according to the specifications of the approved plans, programs and projects, including environmental control measures and other conditions of which they are a determining factor;

3. Operation License: authorizes the operation of the activity or undertaking after verification of the effective compliance to state in the previous licenses, considering the environmental control measures and conditions determined for the operation. 
All of these licenses are part of a single process and are preceded by environmental impact studies and granted. An effort to simplify the licensing process has been discussed in Brazil [9]. Besides these three types of license there are some more specific and less known, but not of minor importance.

It is important to highlight the deadlines in each licensing stage. CONAMA Resolution n. 237 of December 19, 1997 demonstrates that the competent environmental agency can establish different deadlines for the analysis of each type of license depending on the peculiarities of the activity or undertaking to set the limit of six months for the granting or rejection of the application. This period may be extended to twelve months if the object depends on the preparation of an Environmental Impact Study and / or public consultation. The licensing body should establish the minimum and maximum deadlines for each type of license:

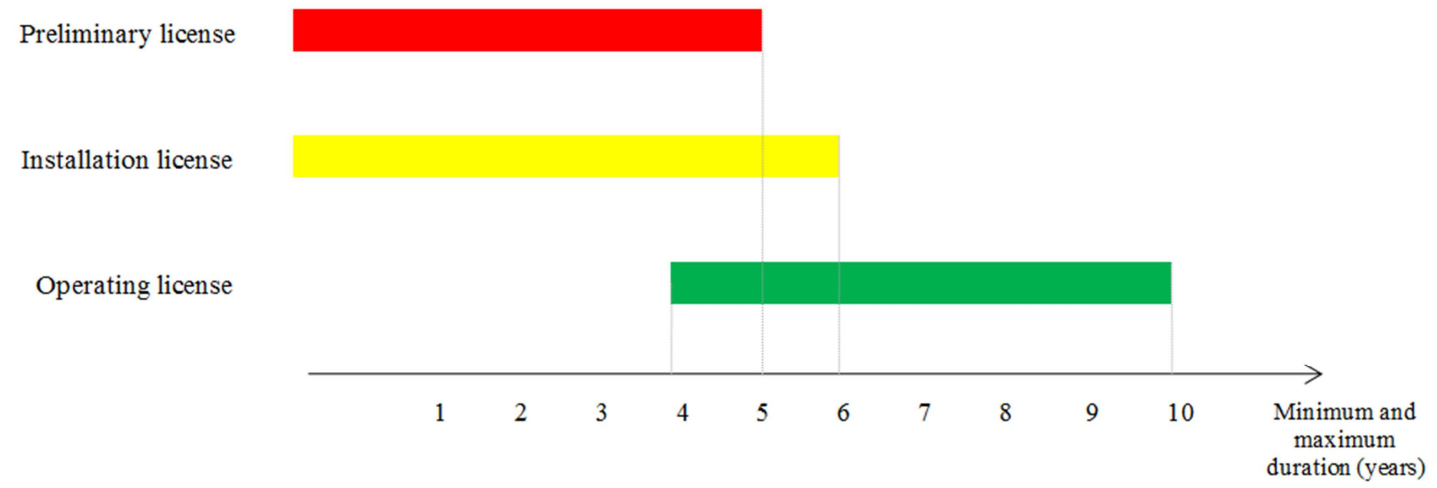

Figure 2. Time duration in licensing process and license types in Brazil.

In the Prior License the minimum term is established by the schedule of preparation plans, programs and projects until five years. For the Installation License the maximum term is also established until six years. For the Operation License are considered the environmental control plans use the minimum term of four years, and the maximum term in ten years. It is important to note that the application for renewal of the Operating License must be presented in advance before the expiration of validity period.

Many human activities need to fit into rules of behavior to ensure the quality of the environment. It uses of natural resources such as inputs or final products. Therefore, environmental licensing has an interface with some professionals, and is subject to State control and cannot be exercised without the prior authorization of environmental agencies [10].

The Law n. 6.938 / 81 that instituted the National Environmental Policy has the mechanisms of formulation and application of environmental licensing. It is also important to consider the activities potentially polluting and users of environmental re-sources cited in this Law. Below are some types of enterprises and activities that need environmental licensing:

1) Mineral extraction and treatment

2) Pulp and paper industry

3) Rubber industry

4) Leather and skins industry

5) Chemical industry

6) Plastic products industry

7) Textile, clothing, shoes and fabrics industry

8) Food and beverage industry

9) Smoke industry

10) Civil works

11) Generation and transmission of energy projects
12) Utility services

13) Transportation, terminals and warehouses

14) Enterprises and Tourism Activities

15) Agricultural activities

16) Use of natural resources

All of the above activities need to pay the Environmental Control and Inspection Fee, which is controlled by IBAMA. The aim of this research was to evaluate and systematically present the evolution of the quantity of licensing in Brazil, of federal responsibility, in the last 11 years and to highlight the licensing typologies in this period.

\section{Methods}

This research has the quantitative approach based on analyzes of environmental licensing processes in Brazil, considering the types of enterprises and productive activities that need to be licensed at the federal level. Here were considered data from 1996 to 2016 that were collected on the IBAMA website. In this research we consider the licenses types in the licensing phases.

\section{Results and Discussion}

The environmental licensing structure in Brazil is unique. Although several models of environmental analysis and evaluation of projects are disclosed has weak information in the technical literature on this subject in the world yet. This hampers a thorough comparative analysis [7] [11]. At the federal level federal environmental assessments are few, fragmented, inconsistent, and late, thus compromising their overall efficiency [12].

This research analyzed federal licensing and which are the enterprises or activities that cause national impacts (when 
they cross the border of Brazil) and regional impacts (when involving more than one State in the country).

The Productive Development Policy was launched with the objective of increasing the country's economic growth in 2008 to help the industrial development and presented results in employment increase and increased competitiveness. On the same year the number of licenses began to rise together with the growth of the industrial sector, causing an improvement in the trade balance and a decrease in social and economic inequalities.

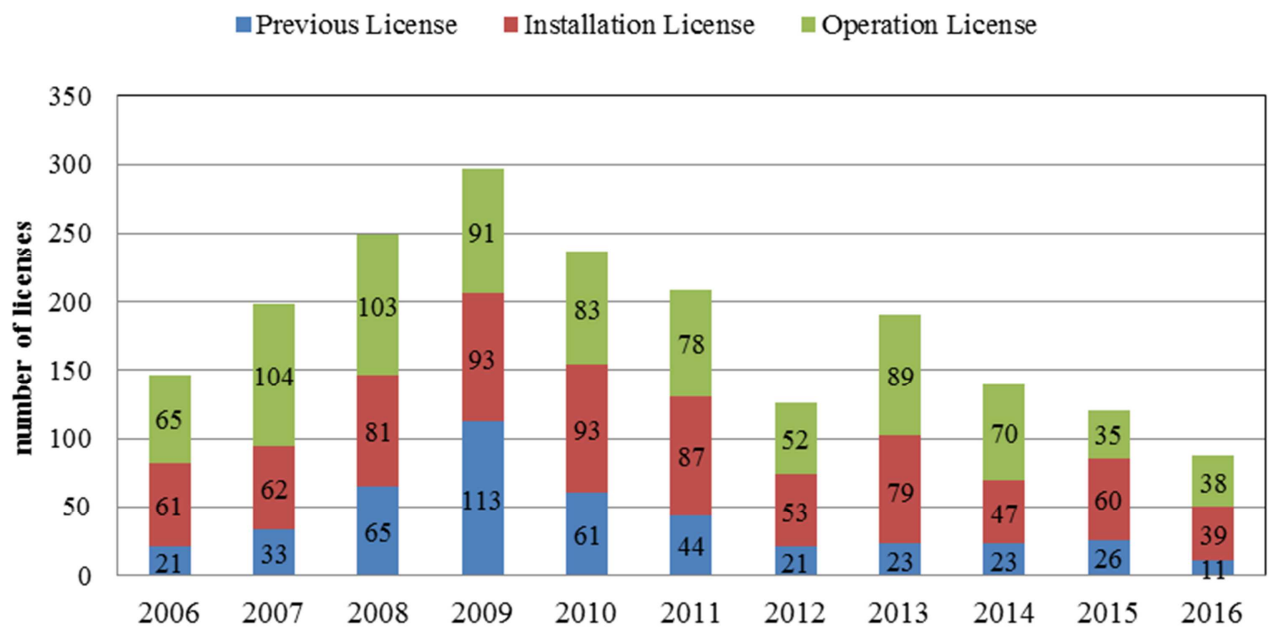

Figure 3. Distribution of license types and their evolution in the last 11 years.

The licensing for the construction and operation of highways prevailed in 2008 and this theme was priority until 2012. It demonstrates the attention of the federal government to increase the road infrastructure in Brazil for the distribution of production of industrial activity.

The topic Transmission Lines of Electric Energy presented a decrease of Previous Licenses in 2009. Data from 2012 until 2016 also demonstrated the largest number of licenses for this type of enterprise. Perhaps the regulation for this type of business in Brazil (updated in 2011 to solve critical aspects) may justify the increase in demand in this business area. In 2015 the highest number of Previous License for this topic was found.

The construction of highways was the greater demand of the Installation Licenses in the last 11 years. The period of 2010 was the year with the highest number of licenses of this type. In 2010 more than ten states of the country were benefited in road infrastructure.

The highest value found in the historical series for Operation Licenses was in 2007. During this period the highway construction licenses accounted for about $57 \%$ of the total and the highest value found in the historical series.

\section{Conclusion}

The IBAMA is responsible for $1 \%$ of the licenses authorized in Brazil. The others are made by the States. The increase or decrease in the number of licenses is induced by demands that not forget to preserve and conserve the environment and prevent disasters. In Brazil the environmental licensing is mandatory for almost 40 years, but the law still does not make clear how to do it. The CONAMA Resolutions are by sectors and very important but it does not have a specific law and it generates legal uncertainty.

The deficiency of federal laws generates a legal uncertainty at all levels (municipal, regional, national). Currently there is an offensive of certain productive sectors (agriculture, forestry, and livestock) to be exempted from environmental licensing. Is necessary construct a standardization of the law and preserve the local specificities. Therefore is necessary a connection between licensor and entrepreneurs to improve the quality of environmental studies and increase the effectiveness of the inspection. The environmental licensing should be a procedure capable of consolidating the application of sustainable measures for environmental and economic development of country.

\section{References}

[1] Ramos, T. B.: Development of regional sustainability indicators and the role of academia in this process: the Portuguese Practice. Journal of Cleaner Production 17, 11011115 (2009).

[2] Batalhão, A. C. S., Teixeira, D.: Indicators Approaches in Municipal Sustainability. New Academic Editions, Saarbrücken (2017).

[3] Batalhão, A. C. S., Teixeira, D., Godoi, E. L.: The Barometer of Sustainability as a monitoring tool of the sustainable development process in Ribeirão Preto, Brazil. ICUR2016 Proceedings, 583-589, Lisbon (2016).

[4] Azevedo-Alves, V. M., Fearnside, P. M., Oliveira, C. S., Padial, A. A., Pelicice, F. M., Lima, D. P., Simberloff, D., Lovejoy, T. E., Magalhães, A. L. B., Orsi, M. L., Agostinho, A. A., Esteves, F. A., Pompeu, P. S., Laurance, W. F., Petrere, M., Mormul, R. P., Vitule, J. R. S.: Removing the abyss between conservation science and policy decisions in Brazil. Biodiversity and Conservation, 26 (7), 1745-1752 (2017). 
[5] Fonseca, A., Rodrigues, S. E.: The attractive concept of simplicity in environmental impact assessment: Perception of outcomes in southeastern Brazil. Environmental Impact Assessment Review, 67, 101-108 (2017).

[6] Roma, J. C., Pêgo, B.: Environmental Licensing in Brazil. Regional, Urban and Environmental Bulletin /IPEA 15, 93-95 (2016).

[7] Verocai, I.:

http://www.mma.gov.br/estruturas/DAI/arquivos/iaraverocai2. pdf, last accessed 2017/03/21

[8] Oliveira, F. S. D., Prado Filho, J. F., Rocha, C. F., Fonseca, A.: Simplified environmental licensing in the southeast region of Brazil: concepts, procedures and implications. Development and Environment 38, 461-479 (2016).

[9] Bragagnolo, C., Carvalho-Lemos, C., Ladle, R. J., Pellin, A. Streamlining or sidestepping? Political pressure to revise environmental licensing and EIA in Brazil. Environmental Impact Assessment Review, 65, 86-90 (2017).

[10] Farias, T.: Environmental Licensing: Theoretical and practical aspects. Forum, Belo Horizonte (2007).

[11] Cordes, E. E., Jones, D. O. B., Schlacher, T. A., Amon, D. J, Bernardino A. F., Brooke, S., Carney, R., De Leo, D. M. Dunlop, K. M., Escobar-Briones, E., Gates, A. R., Genio, L., Gobin, J., Henry, L. A., Herrera, S., Hoyt, S., Joye, S., Kark, S., Mestre, N. C., Metaxas, A., Pfeifer, S., Sink, K., Sweetman, A. K., Witte, U.: Environmental impacts of the deep-water oil and gas industry: a review to guide management strategies. Front. Environ. Sci., 4 (58), 1-26 (2016).

[12] Gibson, R. B.: In full retreat: the Canadian government's new environmental assessment law undoes decades of progress. Impact Assessment and Project Appraisal, 30, 179-188 (2012). 